\title{
Antiviral and antibacterial lipids in human milk and infant formula feeds
}

\author{
Charles E Isaacs, Sudha Kashyap, William C Heird, Halldor Thormar
}

\begin{abstract}
Human milk and two infant formula feeds were tested for antiviral and antibacterial activity before being given to 21 low birthweight (LBW) infants; neither was present. When samples were aspirated from the stomachs of the infants within one to three hours of feeding, however, they reduced titres of enveloped virus and also killed both Staphylococcus epidermidis and Escherichia coli. The lipid fraction of the gastric aspirate from an infant who had been given human milk as well as those from four infants who had been given a conventional LBW infant formula feed, showed antiviral and antibacterial activities at least equal to the activities of the unfractionated aspirates. There was no consistent difference in antiviral or antibacterial activity of either the stomach aspirates or the lipid fractions of these aspirates between infants given human milk and those given formula feeds. The antiviral and antibacterial activities of the gastric aspirates seem to result from intragastric production of monoglycerides and fatty acids from the triglyceride content of the ingested feeds.
\end{abstract}

Breast fed infants seem to have fewer severe gastrointestinal and respiratory infections during the first year of life than formula fed infants. ${ }^{1-4}$ It was previously assumed that the protective effect of breast feeding was conferred by the immunoglobulins, cells, specific antibacterial factors, other immunological components of human milk, or a combination. It is now recognised, however, that the triglyceride content of human milk represents another potentially important anti-infective property. The fatty acids and monoglycerides released when the triglyceride is hydrolysed, either in vitro by the lipases of human milk or in vivo by the lipases of the gastrointestinal tract, are potent inactivators of enveloped viruses as well as of Giardia lamblia. ${ }^{5-13}$ Because formula feeds also contain triglycerides that are hydrolysed in vivo by the same lipases, this anti-infective property of human milk should theoretically be shared by the formula feeds.

The study reported here shows that aspirates from the stomachs of low birthweight (LBW) infants who were fed with human milk or one of two infant formula feeds did inactivate enveloped viruses as well as kill bacteria, and that this antiviral and antibacterial activity is present in the lipid fraction of the aspirates.
Patients and methods

Human milk and formula feeds given to LBW infants in studies of growth, nutrient retention, and metabolic response to particular types of food were tested for antiviral and antibacterial activity both before feeding and after aspiration from the infants' stomachs one hour and, in some, three hours after feeding. ${ }^{14} 15$ Lipid fractions of the gastric aspirates from infants fed human milk and infants fed a conventional LBW infant formula feed were also tested for antiviral and antibacterial activity.

Samples of human milk and formula were obtained from the container before feeding. Samples of stomach contents (1-2 ml) were obtained through an indwelling nasogastric tube. All samples were frozen immediately to $-70^{\circ} \mathrm{C}$, and lipid extraction and assays of antiviral and antibacterial activities were performed later.

Infants participating in this study were either enrolled in previous nutrition studies, ${ }^{14}{ }^{15}$ or selected randomly from among those infants who were receiving at least $180 \mathrm{ml} / \mathrm{kg} /$ day of conventional LBW formula feeds on the days selected for obtaining samples (nine days over a 23 month period). The clinical characteristics of the infants are summarised in tables 1 and 2 .

All human milk preparations were provided by the infants' mothers and were not pasteurised. Some contained a supplement of cows' milk protein (60:40 blend of whey proteins and caseins), calcium, phosphorus, and sodium. ${ }^{14}$ The protein content $(16-22 \mathrm{~g} / \mathrm{l})$ of both the formula feeds studied and the conventional formulas was a $60: 40$ blend of cows' milk whey proteins and caseins. The fat content $(33-41 \mathrm{~g} / \mathrm{l})$ of the formula feeds was a mixture of medium chain triglycerides (50\%), corn oil, and coconut oil, ${ }^{15}$ and that of the conventional formula feeds $(34-41 \mathrm{~g} / \mathrm{l})$ was a mixture of medium chain triglycerides $(40 \%)$, soy oil, and coconut oil. The carbohydrate content of all formula feeds was a mixture of lactose and corn syrup solids. The calcium content of all formula feeds was high (19.96-29.94 $\mathrm{mmol} / \mathrm{l})$.

The lipid content of the gastric aspirates from four infants (one fed both human milk and a conventional LBW infant formula feed and the other three fed just a conventional LBW infant formula feed), as well as the unfed human milk or formula, was extracted by the method described by Jeejeebhoy et al. ${ }^{16}$ This is a quantitative method that extracts both polar and non-polar lipids; the lipid fraction, therefore, contains fatty acids and monoglycerides as well as triglycerides.

Viral infectivity was measured by inoculation 
Table 1 Clinical characteristics of study groups, and antiviral and antibacterial activity of gastric aspirates obtained one hour after taking human milk or an infant formula feed

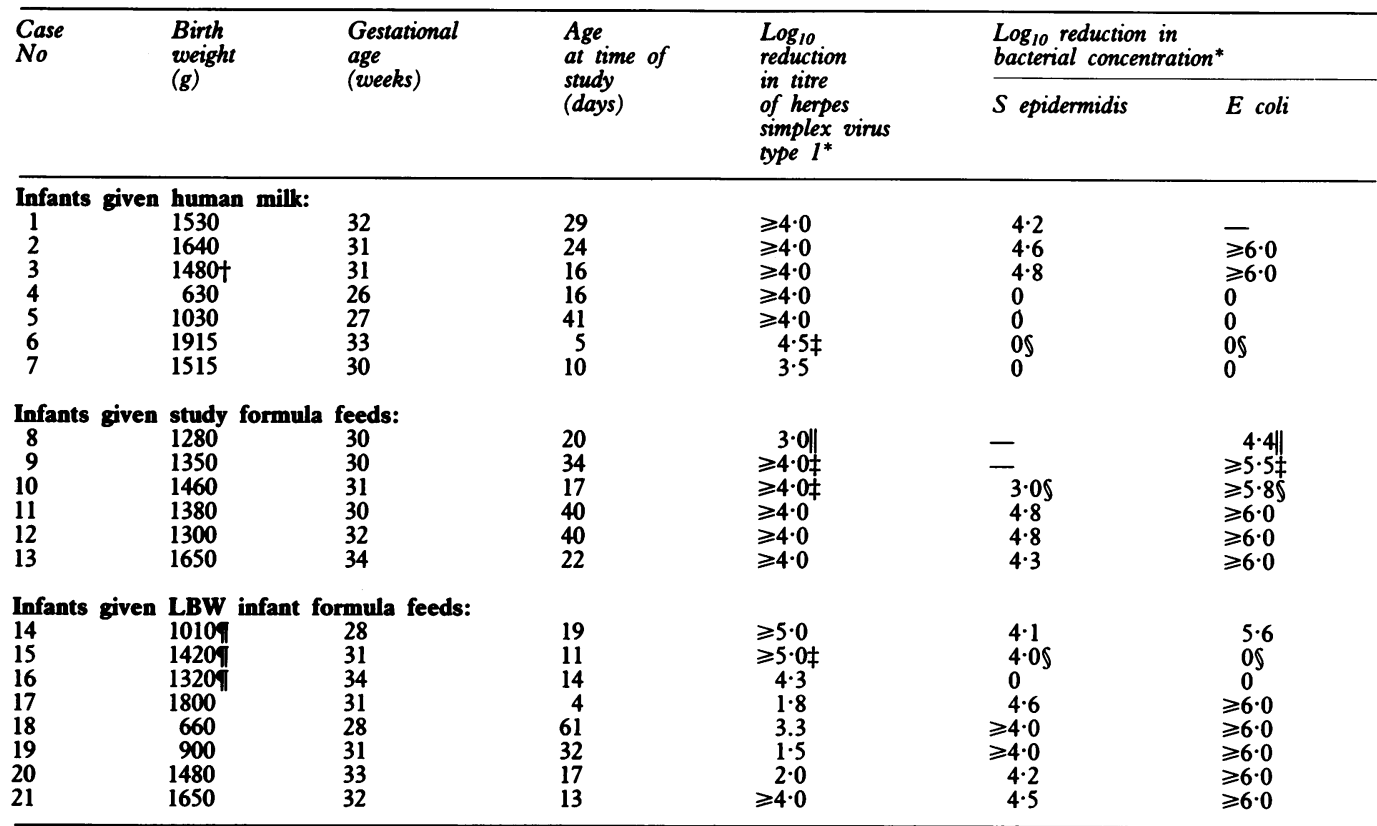

*When $\log _{10}$ reduction values are preceded by $\geqslant$ it indicates that all the test organisms were inactivated. All other values represent the decrease in titre of the test organisms when compared with the control values as described in the patients and methods. All comparisons decrease in titre of the test organisms when compared with the control values

fInfant was fed human milk provided by mother plus a supplement of bovine milk protein, calcium, phosphorus, and sodium ${ }^{14}$; other infants in group were fed milk provided by mother with no supplement.

¥Aspirate obtained three hours after feeding had antiviral activity.

Aspirate obtained three hours after feeding had antibacterial activity $\left(\geqslant 4.0 \log _{10}\right)$.

Aspirate obtained three hours after feeding had neither antiviral nor antibacterial activity

IInfants were given Similac Special Care (Ross Laboratories); other infants in group were given Enfamil Premature (Mead-Johnson Nutritionals).

Table 2 Clinical characteristics of the study groups, and antiviral and antibacterial activities of the lipid fraction of gastric aspirates obtained one hour after feeding from $L B W$ infants given human milk or formula feeds

\begin{tabular}{|c|c|c|c|c|c|c|}
\hline \multirow[t]{2}{*}{$\begin{array}{l}\text { Case } \\
\text { No }\end{array}$} & \multirow{2}{*}{$\begin{array}{l}\text { Birth } \\
\text { weight } \\
\text { (g) }\end{array}$} & \multirow{2}{*}{$\begin{array}{l}\text { Gestational } \\
\text { age } \\
\text { (weeks) }\end{array}$} & \multirow{2}{*}{$\begin{array}{l}\text { Age } \\
\text { at time of } \\
\text { study } \\
\text { (days) }\end{array}$} & \multirow{2}{*}{$\begin{array}{l}\log _{10} \\
\text { reduction } \\
\text { in titre } \\
\text { of herpes } \\
\text { simplex virus } \\
\text { type } 1\end{array}$} & \multicolumn{2}{|c|}{$\begin{array}{l}\log _{10} \text { reduction in } \\
\text { bacterial concentration }\end{array}$} \\
\hline & & & & & $S$ epidermidis & E coli \\
\hline $\begin{array}{l}\text { Infants given } \\
22\end{array}$ & $\begin{array}{l}\text { human } \\
970\end{array}$ & milk: & 42 & $\geqslant 4 \cdot 0$ & 0 & $\geqslant 6.0$ \\
\hline $\begin{array}{l}\text { Infants given } \\
23 \\
24 \\
25 \\
26\end{array}$ & $\begin{array}{c}\text { Enfamil } \\
970 \\
1310 \\
630 \\
1060\end{array}$ & $\begin{array}{c}\text { Premature: } \\
28 \\
30 \\
26 \\
29\end{array}$ & $\begin{array}{l}42 \\
21 \\
75 \\
44\end{array}$ & $\begin{array}{l}\geqslant 4 \cdot 0 \\
\geqslant 4 \cdot 0 \\
\geqslant 4 \cdot 0 \\
\geqslant 4 \cdot 0\end{array}$ & $\begin{array}{r}\geqslant 6.0 \\
\geqslant 6.0 \\
5.5 \\
4.8\end{array}$ & $\begin{array}{l}\geqslant 6 \cdot 0 \\
\geqslant 6.0 \\
\geqslant 6.0 \\
\geqslant 6.0\end{array}$ \\
\hline
\end{tabular}

When $\log _{10}$ reduction values are preceded by $\geqslant$ it indicates that all the test organisms were inactivated. All other values represent the decrease in titre of the test organisms when compared with the control values as described in the patients and methods. All comparisons made with control values described in patients and methods section:

of 10-fold dilutions of herpes simplex virus type 1 (strain MacIntyre) and vesicular stomatitis virus (strain Indiana) into Vero cell cultures (African green monkey kidney cell line) in 96 well microtitre tissue culture plates. Vero cells were grown in Eagle basal medium with $10 \%$ inactivated fetal bovine serum. The maintenance medium for Vero cells was Eagle basal medium with $2 \%$ fetal bovine serum and $0 \cdot 1 \%$ gentamicin. A virus dilution $(0.1 \mathrm{ml})$ in maintenance medium was inoculated into each well with four wells dilution. The plates were kept for four days and examined daily for cytopathic effect. Virus titres were calculated by the method described by Reed and Muench. ${ }^{17}$

For assay of antiviral activity of human milk, formula feeds, stomach aspirates, and the lipid fraction of the aspirates, about $10^{5} 50 \%$ tissue culture infective doses of virus were mixed in maintenance medium with a fivefold dilution of human milk, formula feed, stomach con- tents, or the lipid fraction, and incubated at $30^{\circ} \mathrm{C}$ for 30 minutes. Virus mixed with maintenance medium alone was used as a control. After incubation, the infectivity of each mixture was titrated by the serial dilution endpoint method. Tenfold dilutions were made in maintenance medium. The $10^{2}$ to $10^{5}$ dilutions were inoculated into monolayers of Vero cells and the titres of virus measured as described. The difference between the titre $\left(\log _{10}\right)$ of the control virus and the titre of virus plus mixtures of formula feed, human milk, stomach aspirates, or lipid fraction of the stomach aspirated (that is the reduction in the titre of virus) was used as a measure of antiviral activity.

The bacterium to be tested, either Staphylococcus epidermidis or Escherichia coli (both obtained from the clinical bacteriological laboratory of the New York State Institute for Basic Research), was grown to logarithmic growth phase in nutrient broth. The bacteria, at con- 
centrations of $10^{6} / \mathrm{ml}$ and $10^{5} / \mathrm{ml}$, were then mixed with an equal volume of the human milk, formula feed, stomach aspirate, or lipid fraction of stomach aspirate. After incubation for one hour at $37^{\circ}$, the bacteria were diluted in 10 -fold dilutions, plated on nutrient agar, and incubated overnight at $37^{\circ} \mathrm{C}$, at which time the colonies were counted. Bacterial killing was determined by subtracting the number of colonies on plates of treated bacteria from the number on control plates.

\section{Results}

Antiviral and antibacterial activity were not detected in the solutions before feeding using our assay conditions. As shown in table 1 , however, all aspirates obtained from the stomachs of LBW infants one hour after feeding either human milk or formula feed reduced the titre of herpes simplex virus type 1 by as much as $10^{5}$-fold. Similar antiviral activity against vesicular stomatitis virus, another enveloped virus, was also observed (unpublished observations). Most one hour aspirates also decreased the concentration of $S$ epidermidis by at least $10^{4}$-fold and the concentration of $E$ coli by $10^{6}$ fold.

Stomach aspirates obtained from five infants three hours after they have been fed were also tested for antimicrobial activity. The antiviral activities of four of these five aspirates were comparable at one and three hours; the remaining three hour aspirate had no antiviral activity. The gastric aspirate obtained three hours after feeding from three of four infants also had antibacterial activity either comparable to, or greater than, that of the aspirate taken one hour after feeding, but the three hour aspirate from the remaining infant had no antibacterial activity.

There were only minor differences, if any, in the antiviral activity of the stomach contents of infants who were given human milk compared with those who were given formula feeds. Four of the aspirates taken one hour after feeding from infants who had been given human milk, however, failed to kill either $S$ epidermidis or $E$ coli whereas only one of the aspirates taken one hour after feeding from infants given formula feeds failed to kill either bacterium, and one killed $S$ epidermidis but not $E$ coli.

The antiviral and antibacterial activities of the lipid fraction of gastric aspirates taken one hour after feeding from four additional infants (one fed both human milk and a conventional LBW infant formula feed, and the other three fed the conventional LBW infant formula feed alone) are shown in table 2 . Neither the lipid fraction of human milk nor that of the formula feed had antiviral or antibacterial activity, but the lipid fractions of all five gastric aspirates inactivated herpes simplex virus type one by $10^{4}$-fold, and reduced the concentration of $S$ epidermidis and $E$ coli by $10^{4}$-to $10^{6}$-fold.

\section{Discussion}

The data reported here confirm the theoretical prediction that the lipid associated anti- infective property of human milk is shared by two artificial formula feeds. As the lipid fraction of the gastric aspirates of infants fed both human milk and formula feeds was as effective as the unfractionated aspirate in inactivating herpes simplex type 1 virus, and in killing both $S$ epidermidis and $E$ coli, the effect is obviously derived from a component of the lipid extract of the aspirate that is not present in the human milk and formula feed alone. Although the effects of specific classes of the total lipid fraction of the aspirates on viral inactivation and bacterial killing were not calculated, the most likely candidates are the fatty acids and monoglycerides that are formed from intragastric hydrolysis of triglyceride by gastric or salivary lipase, or both. ${ }^{18} 19$ The method of lipid extraction that we used recovers monoglycerides and free fatty acids as well as triglycerides. ${ }^{16}$ In addition, both monoglycerides and fatty acids are potent inactivators of enveloped viruses, whereas unhydrolysed triglycerides have no effect on them. ${ }^{10}$ Acid and other components of gastric secretions could contribute to the antiviral and antibacterial properties of the aspirates, but these components should not contribute to the antiviral and antibacterial properties of the lipid fraction of the aspirate.

We have previously shown that human milk, after being fed and aspirated from the stomach-but not before being fed-inhibited replication of enveloped viruses. ${ }^{9}$ The data reported here, however, are the first to show that these gastric aspirates also kill $S$ epidermidis and $E$ coli. This is in agreement with the previous work of Canas-Rodriguez and Smith, which showed that the lipid fraction from the stomach contents of suckling rabbits was antibacterial. ${ }^{2021}$ The present study is also the first to show the potential antiviral and antibacterial activity of formula feeds. This latter activity is not surprising. Because there is a wide overlap between the fatty acid pattern of the lipid content of modern formula feeds and that of human milk, one would expect that hydrolysis of the triglyceride of either human milk or formula would release antiviral and antibacterial monoglycerides and fatty acids. Indeed, Hernell et al showed that fresh cows' milk killed $G$ lamblia in vitro after being treated with lipoprotein lipase, but not before. ${ }^{11}$ The necessity for lipase stimulated by bile salts or lipoprotein lipase for the production of the antigiardial effect of human milk was what led earlier investigators to suggest that the lipase was the active agent. $^{22}$

Human milk before feeding did not inactivate the viruses and bacteria used in this study, even though there is evidence that milk contains antibodies and non-specific protective factors-for example, lactoferrin-that are antiviral or antibacterial..$^{5}$ As milk samples were taken from a number of different donors, the lack of detectable antimicrobial activity in undigested milk probably reflects the short incubation time and large inoculum sizes used in the study. If the milk samples had been incubated under the appropriate conditions, the antimicrobial effects of other protective factors in human milk would probably have been detected as well. 
The extent to which the antiviral and antibacterial properties associated with lipids in infant formula feeds and human milk protect the recipient infant against infection is not clear. In the previously cited studies that suggested that breast fed infants had fewer infections than formula fed infants, the control or formula fed infants were undoubtedly fed formula feeds with fat contents similar to those of the formulas which-in the study reported here-inhibited viral replication and killed bacteria. Yet, these formulas clearly were not as protective as human milk. This is probably because human milk contains many factors that help protect against infection, whereas formulas contain only the anti-infective property associated with lipids. With respect to protection against viral infections, the antiviral effect of formula feeds and human milk will protect only against infection by enveloped viruses. Thus, this property will confer no protection against the most common enteric viral infections, the aetiological agents of which are non-enveloped viruses. The other protective factors in human milk, however, would probably help protect against infection by these common enteric viral pathogens.

Thormar et al have shown that some fatty acids are more effective inactivators of enveloped viruses than others, and that the monoglyceride of each fatty acid is more effective than the fatty acid alone. ${ }^{10}$ This obviously suggests that the pattern of fatty acids in the fat content of any diet may be a particularly important determinant of its in vivo antiviral and antibacterial activities. With further research it should therefore be possible to enhance the antiviral and antibacterial effects of a specific diet by altering the pattern of fatty acids in its component triglycerides.

This work was partly supported by funds from the New York State Office of Mental Retardation and Developmental Disabilities and grants HD 13020 and RR 00645 from the National Institutes of Health.

1 Cunningham AS. Morbidity in breast-fed and artificially fed infants. $\mathcal{F}$ Pediatr 1979;95:685-9.
2 Myers MG, Fomon SJ, Koontz FP, McGuiness GA, Lachenbruch PA, Hollingshead R. Respiratory and gastrointestinal illnesses in breast- and formula-fed infants. $A m \mathcal{F} D i s$ Child 1984;138:629-32.

3 Fallot ME, Boyd JL III, Oski FA. Breast-feeding reduces incidence of hospital admissions for infection in infants. Pediatrics 1980;65:1121-4.

4 Cunningham AS. Breast-feeding and health. $\mathcal{F}$ Pediatr 1987; 110:658-9.

5 Goldman AS, Ham Pong AJ, Goldblum RM. Host defenses: developmental and maternal contributions. In: Barness LA, ed. Advances in pediatrics. Vol 32. Chicago: Year Book, LA, ed. Advance

6 Welsh JK, Skurrie IJ, May JT. Use of Semliki Forest virus to identify lipid-mediated antiviral activity and antialphavirus immunoglobulin A in human milk. Infect I mmun 1978;19:395-401

7 Welsh JK, Arsenakis M, Coelen RJ, May JT. Effect of antiviral lipids, heat, and freezing on the activity of viruses in human milk. F Infect Dis 1979;140:322-8.

8 Kabara JJ, Swieczkowski DM, Conley AJ, Truant JP. Fatty acids and derivatives as antimicrobial agents. Antimicrob Agents Chemother 1972;2:23-8.

9 Isaacs CE, Thormar H, Pessolano T. Membrane disruptive effect of human milk: inactivation of enveloped viruses. ₹ Infect Dis 1986;154:966-71.

10 Thormar H, Isaacs CE, Brown HR, Barshatzky MR, Pessolano T. Inactivation of enveloped viruses and killing of cells by fatty acids and monoglycerides. Antimicrob of cells by fatty acids and mo
Agents Chemother 1987;31:27-31.

11 Hernell O, Ward H, Blackberg L, Pereira MEA. Killing of Giardia lamblia by human milk lipases: an effect mediated by lipolysis of milk lipids. $\mathcal{F}$ Infect $D$ is 1986;153:715-20.

12 Rohrer L, Winterhalter KH, Eckert J, Kohler P. Killing of Giardia lamblia by human milk is mediated by unsaturated fatty acids. Antimicrob Agents Chemother 1986;30:254-7.

13 Reiner DS, Wang C-S, Gillin FD. Human milk kills Giardia lamblia by generating toxic lipolytic products. $\mathcal{F}$ Infect Dis 1986;154:825-32.

14 Kashyap S, Schulze KF, Forsyth M, Dell RB, Ramakrishnan $R$, Heird WC. Growth, nutrient retention and metabolic response of low birth weight infants fed supplemented and unsupplemented preterm human milk. Am 7 Clin Nutr 1990;52:254-62.

15 Kashyap S, Schulze KF, Forsyth M, et al. Growth, nutrient retention and metabolic response of low birth weight infants fed varying intakes of protein and energy. 7 Pediatr infants fed varying in $113: 713-21$.

16 Jeejeebhoy KN, Ahmad S, Kozak G. Determination of fecal fats containing both medium- and long-chain triglycerides fats containing both medium- and long-chain trigl

17 Reed LJ, Muench H. A simple method of estimating fifty percent endpoints. American fournal of Hygeine 1938;27. percent

18 Fink CS, Hamosh P, Hamosh M. Fat digestion in the stomach: stability of lingual lipase in the gastric environment. Pediatr Res 1984;18:248-54.

19 Liao TH, Hamosh P, Hamosh M. Fat digestion by lingual lipase: mechanism of lipolysis in the stomach and upper small intestine. Pediatr Res 1984;18:402-9.

20 Canas-Rodriguez A, Smith HW. The identification of the antimicrobial factors of the stomach contents of suckin rabbits. Biochem $\mathcal{F}$ 1966;100:79-82.

21 Smith HW. The antimicrobial activity of the stomach contents of suckling rabbits. Fournal of Pathology and Bacteriology 1966;91:1-9.

22 Gillin FD, Reiner DS, Wang C-S. Human milk kills parasitic intestinal protozoa. Science 1983;221:1290-2. 